\title{
Políticas de promoción de la Economía Social y Solidaria en la comunidad mocoví Com-Caia de Recreo (Santa Fe, Argentina). La construcción de circuitos cortos de comercialización en el período 2012-2017
}

Lucas Gabriel Cardozo

Instituto de Humanidades y Ciencias Sociales del Litoral (IHuCSo, UNL - CONICET), sede Facultad de Ciencias Jurídicas y Sociales. Universidad Nacional del Litoral, Argentina.

Recibido: 4 de noviembre de 2019. Aceptado: 27 de marzo de 2020.

\begin{abstract}
Resumen
A final del año 2003 en Argentina se formula un conjunto de políticas públicas vinculadas a la promoción de la Economía Social y Solidaria desde el Estado nacional. El diseño de dichas políticas tuvo como base las experiencias que se desarrollaron territorialmente en nuestro país en el período de poscrisis. Desde las escalas subnacionales también se impulsaron diseños propios de acciones programáticas estatales de acuerdo con las necesidades locales. En el presente artículo analizamos la implementación de políticas públicas de promoción de la Economía Social y Solidaria en la comunidad mocoví de Recreo de Santa Fe, Argentina, y la construcción de circuitos cortos de comercialización para el período 2012-2017.
\end{abstract}

PALABRAS CLAVE: POLÍTICAS. ECONOMÍA SOCIAL Y SOLIDARIA. TERRITORIO. MOCOVÍ.

Policies to promote the Social and Solidarity Economy in the Mocoví Com-Caia community of Recreo (Santa Fe, Argentina). The construction of short marketing circuits in the period 2012-2017

\begin{abstract}
At the end of 2003 in Argentina, a set of public policies related to the promotion of the Social and Solidarity Economy from the national State were formulated. The design of these policies was based on the experiences that were territorially developed in our country in the post-crisis period. From the sub-national scales, own designs of state programmatic actions were also promoted according to local needs. In this article we analyze the implementation of public policies to promote the Social and Solidarity Economy in the mocoví community of Recreo of Santa Fe, Argentina, and the construction of short marketing circuits for the period 2012-2017.
\end{abstract}

KEYWORDS: POLICIES SOCIAL AND SOLIDARITY ECONOMY. TERRITORY. MOCOVÍ.

PALAVRAS-CHAVE: POLÍTICAS DE ECONOMIA SOCIAL E SOLIDÁRIA. TERRITÓRIO. MOCOVÍ. 
Políticas de promoción de la Economía Social... LUCAS GABRIEL CARDOZO

\section{Introducción}

En un artículo de reciente aparición, Paula (2019) traza un parangón con el pensamiento de Boaventura de Sousa Santos sobre las sociologías de las "ausencias y las emergencias" para rediscutirlo en el campo de la Geografía y, de esta manera, demostrar cómo en nuestra disciplina algunas temáticas quedaron al margen y otras cobraron mayor visibilidad. La comprensión de las geografías de las ausencias y las emergencias desde la dimensión espacial se enfoca en los estudios realizados por geógrafos y geógrafas que deciden, en determinados procesos, (in)visibilizar a ciertos sujetos del espacio.

Posicionándonos en este último campo de las geografías de las emergencias, en el cual aún ciertos procesos territoriales no han sido lo suficientemente abordados o hay escasa producción académica al respecto, analizamos la promoción de las políticas públicas de la Economía Social y Solidaria (en adelante ESS) y su implementación en una comunidad indígena mocoví en la localidad de Recreo, Santa Fe (Argentina). El objetivo es reconstruir cómo esta política especifica construye circuitos de comercialización cortos en el período 2012-2017.

Este caso particular nos permite sistematizar ciertas producciones que se han realizado en una temática, justamente emergente, como lo es la ESS en el período de posconvertibilidad argentino y su institucionalización como política pública, en términos de acciones programáticas para ciertos sectores de la sociedad a escala nacional y subnacional.

El enfoque del artículo es cualitativo, utiliza técnicas de recolección de información en el trabajo de campo, tales como entrevistas en profundidad a miembros de la comunidad Com-Caia, técnicos y técnicas de diversas áreas estatales, tanto provinciales y nacionales; observaciones participantes en asambleas comunitarias (con el debido permiso del consejo comunal) y, además, la lectura y análisis de fuentes secundarias de documentación pública (expedientes, formularios y proyectos), específicamente ligadas a las políticas de promoción de la ESS. Es dable mencionar que para la presentación del artículo se solicitó el consentimiento de los sujetos entrevistados, incluso se pautó la publicación del nombre de las organizaciones y se guardó la confidencialidad de algunos de los testimonios.

Para dar cuenta de lo que expresamos en los párrafos anteriores, el artículo se encuentra estructurado de la siguiente manera. En primer lugar, presentamos las experiencias de ESS como campo emergente en la Argentina reciente. Vinculado a ello, en segundo lugar, señalamos cómo las mismas se traducen en políticas públicas a finales del año 2003 y cómo se definen y caracterizan desde la academia debido a la importancia que estas asumen en la promoción del trabajo asociativo y autogestivo. En tercer lugar, introducimos una breve discusión sobre el territorio y sus diferentes acepciones desde Latinoamérica, centrándonos en aquella vinculada con la política pública, para relacionarla con nuestro caso de estudio: la comunidad mocoví de Campo San José de Recreo, que se describe en el apartado cuarto. En quinto lugar, analizamos y periodizamos a las políticas de promoción de la ESS de diferentes escalas que, más allá de los resultados esperados, posibilitan y generan circuitos de comercialización cortos de hortalizas y verduras a partir del acompañamiento de los técnicos provinciales, nacionales y de militantes de diferentes organizaciones sociales junto a la comunidad mocoví. Por último, presentamos las consideraciones finales de nuestro trabajo, que esperamos puedan abrir nuevos interrogantes para repensar el contenido del artículo para el lector o lectora. 


\section{La economía social y solidaria: emergencias de experiencias en la Argentina reciente}

La ESS adquiere un sentido polisémico en la actualidad de acuerdo con las prácticas y experiencias que se enmarcan en dicho concepto. También, el concepto es disputado por la academia, los movimientos sociales y las políticas públicas que lo operacionalizan en experiencias que se adecuen a la realidad o al "deber ser" de la ESS. Hoy en día ha tomado mayor resonancia la Economía Popular como ámbito de discusión y formulación de políticas, la que hasta hace unos años no tenía el reconocimiento necesario para instalarse como una expresión organizada de los sectores populares -tanto urbanos como rurales- de la Argentina. ${ }^{1}$

La construcción de la ESS, desde la propuesta académica y política, parte de cambios radicales que contesten al capitalismo a partir de sujetos que lleven a cabo propuestas alternativas donde se busque la racionalidad reproductiva de manera colectiva, en contraposición a la racionalidad instrumental imperante del homo economicus. En palabras de José Luis Coraggio, uno de los principales referentes latinoamericanos en la temática, "se trata de superar la condición de agentes de un sistema alienante y autodestructivo y constituirse conjuntamente en sujetos colectivos con capacidad y voluntad para pensar alternativas de acción, de institucionalización de los comportamientos económicos bajo la primacía de la racionalidad reproductiva” (2012:2-3).

La ESS presenta una ruptura con las formas económicas predominantes, intenta capturar y visibilizar las formas solidarias que promueven los sujetos colectivos de manera autónoma, pero también articulados con otras organizaciones sociales de la sociedad civil, favoreciendo la conformación de espacios de lucha, resistencia y disputa a las formas impuestas por el mercado capitalista. Si bien estas experiencias no siempre se evidencian de forma "pura", y lejos de caer en la utopía que no permite reflexionar críticamente, es necesario, como indica Coraggio, tener en cuenta que

(...) [las] experiencias que no son un punto de llegada a consolidar, cristalizándolos, sino parte de una transición necesaria, abierta, contradictoria, iniciada dentro del mismo sistema que intenta superar, con la perspectiva de otras relaciones posibles entre economía, sociedad y política (2017:13).

En este sentido, en el desarrollo teórico de la ESS se pueden destacar dos grandes grupos conformes al espacio-tiempo de desarrollo de las experiencias. Diferentes autores distinguen entre la Economía Social Histórica o Tradicional (Vuotto, 2014) y la Nueva Economía Social y Solidaria (Abramovich y Vázquez, 2007; Coraggio, 2007). ${ }^{2}$

1 En el presente artículo no vamos a ahondar en la discusión sobre la Economía Popular, aunque destacamos que la misma se ha convertido en una categoría en boga, especialmente a partir de la Ley $\mathrm{N}^{\circ} 27.345$ de Emergencia Social. En el marco de esta Ley, se crea en la órbita del Ministerio de Desarrollo Social el Consejo de la Economía Popular y el Salario Social Complementario y el Registro Nacional de la Economía Popular para la inscripción de los trabajadores que serán alcanzados por las acciones establecidas en la Ley (Hopp 2017). Cabe destacar que los movimientos sociales que impulsaron la Ley fueron (y no exclusivamente, pero sí de acuerdo con la correlación de fuerzas que ejercieron) la Confederación de Trabajadores de la Economía Popular (CTEP), el Movimiento Evita, Barrios de Pie y la Corriente Clasista y Combativa.

2 Podríamos agregar a esta división la diferenciación entre del Norte y del Sur. Autores como Mutuberría Lazarini (2010), Oxoby (2010), Forni y Dzembrowski (2010) y Casaccia (2016) señalan que el Norte (específicamente Europa, EEUU y Canadá) se caracteriza por una fuerte vinculación con el tercer sector, las empresas sociales y las cooperativas y mutuales formalizadas; en tanto en el Sur (América del Sur), hay una fuerte 
Desde el punto de vista histórico, la denominada Economía Social Histórica o Tradicional hace referencia a aquellas respuestas colectivas a los efectos sociales de la Revolución Industrial en pleno siglo XIX en Europa. En esta línea, podemos destacar los aportes de dos autores cuyas obras fueron conocidas en Inglaterra y en Francia; el primero de ellos es Robert Owen (1771-1858) y el segundo Charles Fourier (1772-1837). Las experiencias ideadas por estos dos activistas e intelectuales son las primeras manifestaciones asociativas de esta Economía Social fundante y, como lo expresa Vuotto (2009:104), son los inspiradores del "sindicalismo, las cooperativas y las mutualidades, y más ampliamente de la Economía Social”. Ante las desigualdades sociales de aquellos tiempos, las luchas por alcanzar mejoras en las condiciones de trabajo y de vida en general se erigen como las principales razones para el nacimiento de estas asociaciones. ${ }^{3}$ Quizás, el ejemplo más conocido como hito del surgimiento del cooperativismo se encuentra al calor de la Revolución Industrial en 1844, donde los Pioneros de Rochal constituyen la Rochdale Society of Equitable Pioneers bajo las influencias de los idearios Robert Owen, en Lancashire, Inglaterra.

Si bien no es nuestro objetivo profundizar en la temática, es importante destacar que dichas experiencias tienen su correlato en América Latina, y en Argentina en particular, con la llegada de la inmigración europea que a partir de las tradiciones ideológicas de las corrientes socialistas y anarquistas establecieron las primeras cooperativas de trabajo vinculadas a la ayuda mutua, específicamente en el espacio agrario (Carricart, 2012), y también tuvieron gran desarrollo con la expansión de la infraestructura de servicios a principios del siglo XX, donde el Estado no intervenía (Vuotto, 2011).

La Nueva Economía Social y Solidaria cobra visibilidad a partir de la etapa de crisis de la Argentina en 2001. Sin embargo, podemos mencionar que algunas experiencias comienzan a partir de la década del 9o, con la reestructuración económica y el avance neoliberal donde muchas industrias nacionales tuvieron que cerrar sus puertas debido a la apertura comercial del país. La desimplicación selectiva del Estado (Fernández, 2001) en la política económica generó, por un lado, la expulsión de miles de trabajadores de sus puestos laborales y, por otro, una recolectivización tanto subjetiva como material de trabajadores que dieron lucha por conservar el trabajo, estableciendo un conflicto entre el trabajo y el capital (Wyczykier, 2009). En esta etapa los movimientos sociales tienen un rol destacado en la organización de los trabajadores desocupados. Como menciona Tobío (2010:7) es la etapa de la "desinscripción de los colectivos sociales de la protección", dando paso a "los movimientos populares [que] se ven en la necesidad de asumir cada vez en mayor medida la responsabilidad sobre la producción y reproducción de sus condiciones de vida”. De acuerdo con la perspectiva del geógrafo, aquí comienza un proceso de construcción de una territorialidad en tensión entre los movimientos sociales y el Estado, donde comienzan a tejerse diversas redes de base territorial y se toman las calles y las rutas. También podemos señalar, en la misma línea, el trabajo de Svampa (2000) quien reconoce estos cambios estructurales del mundo del trabajo y la resignificación de las identidades "astilladas" en la trama de la vida cotidiana de los viejos trabajadores industriales y cómo desde abajo empiezan a organizar los repertorios de las luchas desde los barrios del conurbano bonaerense.

presencia de las cooperativas y mutuales históricas, pero los movimientos sociales tienen relevancia en las nuevas formas de organización del trabajo asociativo con un gran contenido político.

3 Para ampliar sobre la perspectiva de Owen y Fourier ver Jurado y Cardozo (2016) 
Entonces, teniendo como antecedente la cuestión social de los 90, y en el marco de la profundización de la crisis económica, política e institucional de nuestro país en 2001, signada por la creciente vulnerabilidad social de los sujetos que posteriormente evidenciaron el estallido social, se visibiliza lo que North y Huber (2004) denominan "el argentinazo". Los autores señalan que el período 2001-2003 implica la creación de espacios alternativos, en su mayoría autoconvocados, desplegados por las tácticas de los sectores populares frente la intolerable situación de conflictos sociales de largo tiempo. Ante esta situación, y frente el colapso de la economía nacional, comenzaron a emerger, desde vastos sectores populares, estrategias de supervivencia y colaboración mutua con el objetivo de dar respuesta a sus demandas reproductivas. Estas fueron construyendo nuevos espacios sostenidos en su práctica por valores, principios y acciones contrapuestas a las lógicas mercantiles, cuyo principal fin es la satisfacción de las necesidades del colectivo social al cual pertenecen y desde el que se constituyen. Sin embargo, muchas veces, las mismas se presentan desarticuladas, desordenadas y versátiles. Verónica Gago las ha denominado "ensamblajes heterogéneos" que revelan el "carácter contingente y ambiguo” (2014:18) de las formas de organización comunitarias.

Por lo tanto, durante la etapa de crisis emergieron experiencias que rápidamente se instalaron en la sociedad, específicamente en los grandes aglomerados urbanos del país. En la actualidad, y casi a dos décadas de experiencias empíricas de ESS, se pueden mencionar las siguientes: ${ }^{4}$ microemprendimientos familiares; asambleas barriales (Federico-Sabaté, 2014 y Farias, 2018); nuevas cooperativas (especialmente aquellas impulsadas por programas del Estado nacional); redes de trueque (Hintze, 2003) y comercio justo (Cuatrín et al., 2016; Orzuza et al., 2015); mercados solidarios y monedas sociales (Orzi, 2012); la vuelta de las ferias populares en las diferentes plazas de las ciudades (Robledo, 2014); las finanzas solidarias como instrumentos de acceso al crédito (Muñoz, 2017a); fábricas recuperadas y consolidación de emprendimientos productivos de movimientos piqueteros y movimientos sociales (Wyczykier, 2009); creación de espacios culturales gratuitos para la comunidad y acceso a la educación a través de los bachilleratos populares; la organización de las mujeres para el trabajo en actividades no tradicionales (mujeres albañiles) y la economía de los cuidados (Quiroga Díaz, 2009); cooperativas de software libre, entre otros.

Desde los espacios rurales también se impulsaron experiencias de ESS que en estos últimos años cobraron relevancia. Entre ellas podemos mencionar: fomento de la agricultura familiar, mujeres rurales, trabajadores rurales sin tierra, pescadores artesanales, cooperativas de pastores, comunidades indígenas organizadas, agricultores del periurbano o ferias francas, por mencionar algunos (Cittadini et al., 2010; Caballero, $2014 \mathrm{y}$ Del Compare, 2014). Las diversas formas de reproducción ampliada los modos de vida campesinos e indígenas se contraponen a la ruralidad hegemónica globalizada (Wharren y García Guerreiro, 2014), colocando el énfasis en la disputa por el uso de la tierra y la defensa de una producción diversa, opuesta a los sistemas orientados exclusivamente a los commodities que conllevan la destrucción de los sistemas productivos locales de alimentos básicos. En sentido amplio, se plantea una reivindicación de los saberes locales y lucha por la sobrevivencia de las economías regionales. Las disputas de los

4 El impacto de las principales transformaciones económicas del gobierno de la Alianza Cambiemos, (Santarcángelo et al., 2019), afectó considerablemente a los sectores populares. Las experiencias señaladas resurgen en los diferentes barrios de las ciudades argentinas demostrando que reaparece la memoria de la organización colectiva (ver: Gandulfo, 2017; Notiamérica, 2018 y Lutzky, 2019). 
campesinos e indígenas ponen de relieve las problemáticas vinculadas, específicamente, a la acumulación del capital a partir de las configuraciones espaciales del agronegocio y sus consecuencias: una ruralidad sin campesinos y campesinas, la expulsión del trabajo y la depredación ambiental junto a la pérdida de biodiversidad.

\section{Las políticas públicas de promoción de la ESS}

Raul Zibechi (2011) reflexiona sobre el rol de las políticas sociales en los países latinoamericanos y cómo estas pudieron trabajar sobre el conflicto y establecer ciertos criterios en la formulación de políticas orientadas al acompañamiento de las experiencias de ESS. En palabras del autor:

(...) los gobiernos progresistas del Cono Sur supieron comprender el fenómeno e interpretaron con audacia teórica y prácticas novedosas, las rupturas implícitas en la nueva generación de movimientos, en gran medida porque sus cuadros y administradores provienen del corazón de ese nuevo activismo de base, de fuerte impronta territorial (2011:36).

En la misma dirección, José Luis Coraggio (2014), en su texto La presencia de la Economía Social y Solidaria y su institucionalización en América Latina, presenta un análisis del surgimiento de la ESS en los países de Latinoamérica: Argentina, Brasil, Bolivia, Ecuador y Venezuela. Destaca cómo se gesta su formalización mediante los marcos legales, los marcos constitucionales (para Ecuador y Bolivia) y también el reconocimiento de las formas organizativas territoriales de la ESS por parte del Estado, para luego formularse como políticas públicas. Sin embargo, aquí no vamos a entrar en el detalle de cada uno de los países, teniendo en cuenta que ya se han realizado estudios que profundizaron en sus especificidades, como es el caso de Hintze (2010) para Brasil y Venezuela, Hopp (2012) para Argentina, Sánchez (2017) para Ecuador, y Wanderley (2016) para Bolivia, por mencionar algunos.

Retomemos brevemente el caso argentino teniendo en cuenta que, a partir del año 2003, las políticas de promoción de la ESS cobran relevancia en una nueva etapa de formulación y diseño de las políticas públicas, específicamente sociales. La reestructuración del Ministerio de Desarrollo Social de la Nación, en el marco de la promoción de una "nueva tradición" de política social con la creación del Programa Nacional Manos a las Obras de Economía Social y Desarrollo Local, significó una apuesta transcendente en la readaptación de las políticas sociales en cuanto a las bases conceptuales que la sustentaban en décadas anteriores, y también conllevó a una importante modificación en la estructura organizacional y circuitos administrativos (Cardozo, 2015). ${ }^{5}$

Dicho programa, sumado a otros que se fueron creando a lo largo del período 2003-2015 fueron discutidos y estudiados en congresos académicos, diferentes foros y encuentros de organizaciones sociales. ${ }^{6}$ Las posturas fueron $-\mathrm{y}$ son- muy diversas sobre las formas

5 También se pueden mencionar los siguientes trabajos que muestran los cambios institucionales/administrativos a nivel nacional: Rebón y Salse (2003); Rebón y Roffler (2006 y 2008); Rebón; Salse y Roffler (2004).

6 Para un análisis detallado de los programas se recomienda la lectura del capítulo de Malena Hopp (2012): "Políticas sociales de empleo en la Argentina post-convertibilidad. Un análisis comparativo de planes de desarrollo socio-productivo" 
de intervención del Estado argentino en materia de la ESS. De hecho, se presentan algunas posturas de carácter asistencialistas y de cooptación de las organizaciones sociales; y otras que destacan el carácter de la hibridación de recursos en términos de Laville y Eme (2004), donde las intervenciones del Estado a través de sus políticas refuerzan los procesos de desarrollo de las experiencias de ESS.

Si bien Hintze (2007) plantea que las políticas de ESS trascienden el campo de las políticas sociales, para el caso argentino, sin embargo, las mismas se desarrollaron inicialmente -con mayor énfasis- en la órbita del Ministerio de Desarrollo Social. Por otro lado, con el transcurso del tiempo, algunos componentes de las políticas de ESS (específicamente la asociatividad y autogestión) fueron siendo incorporadas en otras instancias de los ministerios nacionales.

En sintonía con lo expuesto, Castelao Caruana, (2016) identifica las siguientes políticas de ESS en los ministerios y organismos nacionales para el período 2003-2013:

I. Ministerio de Desarrollo Social: Monotributo Social; Marca Colectiva; Plan Nacional de Desarrollo Local y Economía Social Manos a las Obras, Programa Ingreso Social con Trabajo. Comisión Nacional de Microcrédito: Ley de Microcrédito y Programa Nacional de Microcréditos "Padre Cajade". INAES: Programa de Educación y Capacitación Cooperativa y Mutual; Programa Formación de Formadores y Programa de Ayuda Financiera.

II. Instituto Nacional de Tecnología Industrial: Comercio electrónico, Cadena de valor artesanal, Asistencia a cooperativas y empresas recuperadas, red de apoyo al trabajo popular, programa de unidades productivas, programa de abastecimiento básico comunitario.

III. Ministerio de Turismo: Red Argentina de Turismo Rural Comunitario.

IV. Ministerio de Trabajo, Empleo y Seguridad Social: Competitividad para Empresas Autogestionadas.

V. Ministerio de Planificación Federal, Inversión Pública y Servicios: Plan Federal de Integración Sociocomunitaria por cooperativas y Plan Agua + Trabajo.

Muchas de las investigaciones acerca de las políticas de promoción de la ESS se centran en los resultados de la implementación de los diversos programas nacionales en los territorios locales, sin prestar atención si en las escalas subnacionales existen formulaciones propias de políticas dirigidas a este sector (Massera y Cardozo, 2019). Sin embargo, como antecedentes de estos estudios de niveles provinciales, podemos mencionar el trabajo de Hintze, Deux Marzi y Costa (2011), donde describen y analizan comparativamente los organismos públicos, sus políticas y programas de fomento de la ESS a nivel nacional y provincial, específicamente, de la Ciudad Autónoma de Buenos Aires, Rosario y Córdoba. El estudio demuestra una tendencia respecto a que la creación de dependencias subnacionales se debe a la ejecución de los programas nacionales, incluso como órganos de contralor en sus actividades cotidianas. El artículo publicado en el Observatorio del Conurbano, Ruth Muñoz (2017b) sistematiza las políticas de ESS que se desarrollan en los 24 partidos de la provincia de Buenos Aires en el período 
2011-2015, se destaca la débil institucionalidad, siendo muy pocos los municipios que logran crear sus propias políticas y que, en este sentido, no dependen exclusivamente de la escala nacional, destacando la débil institucionalidad existente

Para el presente trabajo tomamos la definición de las políticas públicas de promoción de la ESS de Susana Hintze (2013) quien las define como aquellas que

(...) constituyen políticas públicas en sentido amplio. Trascienden el subconjunto de las políticas sociales (dentro de las cuales se las ubica en muchos países de América Latina). Siguiendo a Danani, se reserva el término de política social para "aquellas intervenciones sociales del Estado" que producen y moldean de manera directa las condiciones de vida y de reproducción de la vida de los distintos grupos sociales, y lo hacen operando sobre el momento de la distribución secundaria del ingreso a través de mecanismos de redistribución. Esto las distingue de las laborales, que regulan directamente los ingresos del capital y el trabajo, o de la distribución del ingreso, que deriva de manera mediata de la producción (Danani, 2004:11-12). En esos términos incluyen y exceden el campo de las políticas sociales, en la medida en que sus efectos operan también en la redistribución primaria de los ingresos vía apoyo de otras modalidades de trabajo generadoras de ingreso por fuera de la relación capital-trabajo, a la vez que se ocupan de las intervenciones relacionadas con la protección del trabajo asociativo auto-gestionado (en algunos países incluidas las laborales). (Hintze, 2013:34. Destacado en el original).

De esta manera, las políticas de ESS se encargan de promocionar y desarrollar la cuestión socio-productiva vinculada al trabajo autogestionado y asociativo en los territorios, y se enmarcan bajo una estrategia que tiene significado en el campo del Estado en la búsqueda de mejorar las condiciones socioeconómicas de la población. Susana Hintze en diferentes trabajos (2007, 2010, 2013, 2014) y Hintze, Deux Marzi y Costa (2011), señalan una serie de características deseadas ${ }^{7}$ que las políticas públicas de ESS deberían contener:

I. Co-construcción: se entiende a las políticas como "resultado de la intervención de diferentes actores, la creación de alianzas, de redes de movimientos sociales entre sí y el Estado" (Hintze, 2014:25).

II. Intersectorialidad: corresponde a la acción conjunta de diversos organismos dentro de la esfera estatal y entre las diferentes jurisdicciones de organización territorial.

III. Transversalidad: refiere a la posibilidad de imbricación con procesos de desarrollo que lleven adelante otras organizaciones socioeconómicas y se encuentra ligada a la siguiente característica.

IV. Horizontalidad: remite a la relación tanto entre organizaciones socioeconómicas como al interior de una organización para la toma de decisiones. 
V. Participativas: en contraposición de las políticas top-dowm o bottom up, las políticas de ESS tienden a una horizontalidad y dinamismo con procesos conflictivos y de negociación constante entre el Estado y las organizaciones de la sociedad civil.

VI. La gestión de políticas en red: se plantea estudiar las redes que conforman el "conjunto de organizaciones que son corresponsables en procesos de trabajo y se integran para lograr fines comunes. Esto implica acuerdos permanentes y el establecimiento de relaciones de confianza" (Hintze, 2014:24). La autora le asigna un rol estratégico a la gestión en red, pues permite coordinar el espacio institucional en o fuera de los organismos públicos y evitar la "dispersión, fragmentación, superposición” que dificultarían la intersectorialidad y transversalidad.

VII. Territorialización: en su perspectiva de la territorialización, Hintze recupera la noción de territorio como "articulador de actores y recursos", a partir de la capacidad de las organizaciones sociales de "generar procesos de desarrollo a distintas escalas” (2014:23). Para la especialista, es el lugar donde las organizaciones socioeconómicas de la ESS generan recursos materiales y simbólicos. Además, el territorio otorga flexibilidad a la implementación de políticas de ESS.

Si bien todas las características son importantes, y con cada una de ellas se pueden montar una empresa de investigación sobre las diferentes formas de intervención que han desarrollado las políticas públicas en su gestión e implementación, en nuestro trabajo nos interesa retomar la territorialización de las políticas de ESS desde una perspectiva geográfica, para establecer un diálogo con las formas de territorialización de ciertos procesos espaciales de una comunidad indígena y el encuentro con las políticas de ESS. Es decir, como la territorialización de una política de ESS puede acompañar y concretar a otros procesos territoriales.

\section{Territorio como categoría analítica, normativa y práctica}

En la disciplina geográfica, el concepto de territorio adquiere diferente significación de acuerdo con la adscripción teórica de los geógrafos que lo utilizan y desde la óptica con la que observan y analizan los procesos socioespaciales. Sin embargo, el uso del término territorio en los últimos años ha desbordado el campo disciplinar, siendo frecuentes las discusiones en términos territoriales en el concierto de las ciencias sociales (Altschuler, 2013).

En América Latina, de acuerdo con un trabajo realizado por las ecuatorianas López Sandoval, Robertsdotter y Paredes (2017), la deriva del concepto territorio desde la Geografía emerge con fuerza a partir de la década del 80 cuando el termino alcanza diversos tipos de análisis en el marco del proceso de globalización y los cambios políticos, económicos, sociales y culturales que atraviesa la región. De esta manera, en el contexto globalizado, el concepto de territorio comienza a utilizarse en función de tres variantes que identifican las autoras: (i) la académica, las propias conceptualizaciones que se realizan desde la disciplina y los diferentes enfoques y recorridos a partir de la 
interdisciplinaridad con otras ciencias sociales; (ii) la utilización de las organizaciones sociales, a partir de reclamos en clave de defensa y control territorial de las comunidades subalternizadas; y, por último, (iii) las políticas públicas, específicamente a partir de su anclaje en la instrumentalización y difusión de las propuestas de desarrollo territorial, muchas veces entendiendo al territorio como el espacio locacional de implementación de las mismas.

En la misma línea, Rogério Haesbaert (2018) problematiza la categoría de territorio teniendo en cuenta el lugar de enunciación de este, específicamente desde la producción científica de geógrafos (y otros/as cientistas sociales latinoamericanos/as), tomando las coordenadas espacio-tiempo como elementos contextualizadores de la emergencia y centralidad del concepto. Por un lado, realiza un recorrido del mismo como una categoría de análisis academicista a partir de los aportes de autores brasileros como Milton Santos, Robert Moraes, Carlos Walter Porto-Gonçalves y de su autoría. En el análisis rescata los usos del territorio de los autores mencionados y se refiere a procesos y dinámicas socioespaciales periféricas, destacando el punto de vista crítico de las transformaciones operadas por el capitalismo sobre el territorio específicamente brasilero.

Por otro lado, y siguiendo al autor, el territorio cobra otro significado: como categoría de práctica. En esta construcción adquiere relevancia el diálogo, acercamiento y/o intercambio de los autores mencionados con los movimientos sociales, enriqueciendo el concepto y reconociendo las diferentes formas de vivir, luchar y disputar el territorio. La relación con los sectores subalternos, especialmente con los movimientos sociales campesinos e indígenas o con las organizaciones de base urbanas hizo que el concepto adquiera el carácter "nativo" (Haesbaert, 2018:283). Sin embargo, no siempre está en plano de lucha y disputa, sino que también existe un "retraimiento territorial" en los grupos subalternos, entendiéndolo como una estrategia o una pausa en los caminos de reivindicación territorial. Como señala el autor:

La territorialización no siempre implica estar abierto a nuevas conexiones, transitar a través de múltiples redes y escalas geográficas; la territorialización también es, al menos en ciertos momentos o situaciones, protegerse contra el cierre relativo que garantiza nuestro abrigo... Para este refugio y calor necesitamos tener el poder de controlar la apertura y el cierre de nuestros territorios, y que (re) hacernos cuando lo necesitamos o deseamos, sin afectar la autonomía de otros grupos sociales. (Haesbaert, 2018: 286, traducción del autor).

Como señalamos anteriormente en el trabajo de las geógrafas ecuatorianas, Haesbaert (2018) reconoce que en nuestro continente existe una utilización del territorio como categoría normativa, específicamente ligada al Estado. Esta perspectiva nos remite a la conceptualización tradicional de territorio, un espacio delimitado donde el Estado ejerce el poder. Podríamos reconocerla como una perspectiva de arriba hacia abajo, marcada por un proyecto político en el cual los dispositivos estatales cumplen con la función de realizar recortes territoriales para implementar sus programas de diversa índole (educativos, salud, género, seguridad, etc.).

A fines de este trabajo, retomamos los aportes de Arzeno y Alvarez (2017) quienes reconocen la dimensión territorial de las políticas públicas desde una perspectiva relacional y abierta a múltiples expresiones del poder tanto material como simbólica en 
Políticas de promoción de la Economía Social... LUCAS GABRIEL CARDOZO

el territorio. Las autoras identifican que existen negociaciones donde se establecen vínculos y conformación de redes estratégicas de diferentes actores para incidir en el curso de la política pública. Como indican:

(...) partimos de considerar que actores insertos en proyectos de producción y reproducción económica y social de distinta índole y escala inciden en la particular estructuración del territorio y en las políticas públicas que se implementan. Esto implica tener en cuenta en el análisis, quiénes son los actores de peso económico y político a nivel local, qué relaciones establecen entre sí y con otros actores, entre otros, los pequeños productores y cómo juegan en las redes de políticas que se conforman en torno al tema bajo análisis, es decir, qué capacidad tienen para influir, directa o indirectamente, en las negociaciones que se suscitan dentro de esas redes y en términos más generales, en el curso de acción de la política pública en cuestión. (Arzeno y Alvarez, 2017:78-79).

Ahora bien, el territorio como categoría normativa no sólo queda delimitado a las acciones de ciertos actores, sino que, como bien señalan Arzeno y Alvarez (2017), existen diversas posiciones ocupadas por actores y su capacidad de promover u obturar procesos vinculados a la implementación de las políticas públicas. Estas condiciones también dependen de las posiciones de los destinatarios de las políticas. Si retomamos la cuestión de los grupos subalternos, su capacidad de establecer las negociaciones con diversos actores estatales y no estatales para la reproducción de sus vidas pueden crear nuevos procesos socioterritoriales.

En nuestro caso particular, vale preguntarse: ¿̇se pueden llevar a cabo nuevas estrategias de organización socioespacial vinculados a la ESS a partir de la implementación de las políticas de promoción de la ESS? Como indicamos con antelación, nos interesa indagar en un caso particular de una comunidad indígena mocoví de la localidad de Recreo (Santa Fe), como se articula la categoría normativa y los efectos de la territorialización (como característica propia de las políticas de ESS) para la construcción de espacios alternativos de comercialización de producción hortícola.

\section{Políticas públicas de economía social a escala subnacional y la vinculación con la comunidad mocoví Com-Caia}

\section{La institucionalización de las políticas de promoción de la ESS en la provincia de Santa Fe}

Entre los años 2011 y 2015 (segunda gestión provincial del Frente Progresistas Cívico y Social) se construye la institucionalidad de las políticas de ESS y se instala el tema en la agenda provincial. En palabras del Subsecretario:

En el marco de la reconfiguración institucional que significó la creación de la Subsecretaría de Economía Social, se propuso extender territorialmente las políticas de ESS articulándose con aquellas experiencias socioproductivas existentes de modo disperso en el territorio provincial y, paralelamente, propiciando el surgimiento de otras nuevas en aquellos lugares donde las mismas eran inexistentes aprovechando la institucionalidad creada. (Casella, 2015:143). 
De esta manera, el Gobierno de la Provincia de Santa Fe crea la Subsecretaría de Economía Social en la órbita del Ministerio de Desarrollo Social. ${ }^{8}$ Con una serie de acciones específicas, el esquema de trabajo se presentaba a partir del Plan Operativo de Acción (conocido como POA), dirigido a municipios y comunas. El mismo constaba de tres líneas de trabajo: (i) capacitación y asistencia técnica, asesoramiento; (ii) apoyo a la producción y circulación de los productos y servicios, y (iii) financiamiento (a través de microcréditos). Además de otras líneas de acción: el Formulario B, para el trabajo con instituciones de la sociedad civil y la Planilla $A$, que financiaba de manera directa a personas. ${ }^{9}$ Estas acciones eran las propuestas para acceder a las políticas de ESS.

De acuerdo con los entrevistados, la escalada organizacional de la Subsecretaría permitió que la temática de la ESS se trabaje de manera extensiva a nivel territorial, porque no solo se estructuraba un área de trabajo, sino también una temática con alcance a diferentes actores: municipios y comunas, organizaciones sociales y personas físicas.

Atendiendo a lo que expusimos en el apartado anterior, sobre la emergencia de las políticas de ESS en Argentina, una de las preguntas que podríamos realizar es la siguiente: ¿́por qué se institucionaliza la ESS en la provincia en el año 2011, cuando desde la escala nacional esto se logra a principios de 2004? En primer lugar, si bien previamente existían áreas que gestionaban programas de ESS (direcciones de menor rango organizacional), las mismas se encontraban dispersas y no bajo un proyecto común desde el gobierno provincial. En segundo lugar, los intentos por trabajar coordinadamente con las políticas de Nación, específicamente con el Ministerio de Desarrollo Social, se habían intentado en varias oportunidades (a través de la ejecución de programas específicos como el Manos a la Obra) y no funcionaron. A partir de entrevistas a informantes clave, se mencionó que las reuniones se realizaban con los técnicos nacionales, pero luego no se cumplían los acuerdos y, sumado a ello, la escalada de las diferencias políticopartidarias cobraron mayor relevancia entre los niveles de gobierno.

Bajo la misma órbita del Ministerio de Desarrollo Social de la provincia funciona el Instituto Provincial del Aborigen Santafesino (IPAS),${ }^{10}$ el órgano representativo de la cuestión indígena provincial a nivel nacional que participa en debates en torno a sanción de leyes y vehiculiza los programas a implementar provenientes desde nación. Actúa como nexo que posibilita la articulación con políticas de diferentes organismos gubernamentales, por ejemplo, en temas como vivienda, educación y producción (Cardozo, Brasca y Cabré, 2018). También, es el organismo encargado de ejecutar la Ley $\mathrm{N}^{\circ} 12.086 / 2002$, que permite la entrega y reconocimiento de territorios a las comunidades originarias a partir de la adjudicación de lotes fiscales y parcelas de islas. ${ }^{11}$

8 Para ampliar información sobre la temática se recomienda ver Massera y Cardozo (2019).

9 En un informe reciente sobre las políticas de Economía Social de la Provincia de Santa Fe se hace mención a estas acciones (ver Cardozo y Beckman, 2018).

10 En el estatuto, los artículos 8 a 14 de la Ley N¹1.078 especifican la creación de dicha autoridad de aplicación. La misma está constituida por un Presidente, designado por el Poder Ejecutivo, y un Consejo integrado por cinco representantes de comunidades aborígenes. Además, se dispone como órgano consultivo y de asesoramiento a la Organización de Comunidades Aborígenes de Santa Fe (OCASTAFE). Por otro lado, como parte de la reglamentación del artículo № 7, se crea el Registro Especial de Comunidades Aborígenes (RECA), dependiente del Ministerio de Justicia y Derechos Humanos de la provincia.

11 La Ley Provincial $N^{\circ} 12.086$ especifica en su anexo $\mathrm{N}^{\circ} 1$ cuáles son las parcelas disponibles para hacer entrega a las comunidades. Para acceder a tierras, las comunidades deben estar registradas en el RECA donde obtienen reconocimiento provincial. Una vez adjudicadas las tierras de forma permanente tienen el reconocimiento de su propiedad comunitaria y las pueden inscribir a su nombre, siendo la posesión y la propiedad 
En el contexto de efervescencia de gestión de políticas de ESS en la Provincia, ${ }^{12}$ se comienza a trabajar intersectorialmente con el IPAS y la primera experiencia se realiza con la comunidad mocoví de Recreo. En este sentido, la ESS se transforma en una estrategia para promocionar emprendimientos socioproductivos en las comunidades indígenas de la provincia, fomentando al trabajo asociativo y autogestivo desde la política pública.

\section{Hacia una geografía mocoví en Santa Fe}

Los mocovíes, habitan la zona sur de la región chaqueña, en la República Argentina, junto con otros indígenas del grupo lingüístico guaycurú (Citro, 2006). La comunidad mocoví Com-Caia se encuentra radicada en la localidad de Recreo, sus miembros son oriundos del norte de la provincia de Santa Fe y sur de Chaco (Chaco austral) y provienen de Colonia Dolores, San Javier, Romang, San Roque, Margarita y Calchaquí (Citro, 2006; Gualdieri y Citro, 2006). Hasta mediados del siglo XX, el pueblo mocoví se encontraba sometido a persecuciones sostenidas desde del Estado por no encontrarse bajo el régimen occidental de pautas culturales. A fin de sobrevivir, se incorporaban al sistema de vida del "blanco", como peones, jornaleros, servicio doméstico y criadas, como así también, otros se refugiaban en los montes o en las islas continuando con sus formas de vida tradicional (Benzi, 2017).

Hacia fines de la década del 6o, ocurre un éxodo migratorio de mocovíes del norte de las provincias de Santa Fe y del Chaco producto de la mecanización agraria y la reconfiguración de los mercados de trabajo, en los cuales eran contratados como mano de obra (algodonero, maicero, sobre todo). Los diferentes destinos migratorios fueron la provincia de Buenos Aires (Engelman, Weis y Valverde, 2016) y la zona centro-sur de la provincia de Santa Fe (Citro, 2006), mientras que los desplazamientos espaciales se articulaban bajo las redes sociales de parentesco o por amistad. En la región centro de la provincia de Santa Fe, se ubicaron en las localidades de Recreo y Montevera para trabajar principalmente en la horticultura (Cardozo y Benzi, 2019). Cabe destacar que las dos localidades mencionadas pertenecen al cinturón hortícola de Santa Fe, conformando un periurbano con fuerte presencia de zonas de quintas de producción de hortalizas y vegetales para el abastecimiento del mercado interno provincial (INTA, 2012; Fritschy y Cardoso, 2014). Sin embargo, actualmente estas localidades se encuentran bajo la tensión de las transformaciones propias del mercado inmobiliario y la expansión de otros usos del suelo no tradicionales del espacio rural (Mantovani y Peralta Flores, 2015 y Cardoso, 2018).

de sus tierras inembargables, imprescriptibles, inajenables y libres de impuestos en el Registro General de la Propiedad y Catastro de la Provincia de Santa Fe (ver Cabré, 2018).

12 El surgimiento de políticas a nivel subnacional fue acompañado por iniciativas desde las organizaciones sociales para crear normativas de regulación y desarrollo de leyes de fortalecimiento de la ESS. Para el caso santafesino, la tesis de maestría de Erika Beckman (2018) analiza la institucionalidad de las políticas de ESS y la relación de las organizaciones de la sociedad civil y el Estado en el proyecto de ley elaborado, consensuado en los foros territoriales de la provincia y los conflictos derivados del veto a la Ley N 13.516/16 de Promoción y Fomento a la Economía Social y Solidaria realizado por el ejecutivo provincial. Blasco y García (2017) recogen las normativas que se constituyen en una instancia de negociación entre los gobiernos locales y provinciales y los colectivos vinculados a la ESS en diferentes provincias, para crear marcos legales que respalden el trabajo autogestionado y asociativo para los casos de las provincias de Mendoza, Río Negro, Entre Ríos y Santa Fe. 
En la actualidad, en la localidad de Recreo se encuentra la comunidad mocoví Com-Caia dividida en dos nucleamientos (ver Figura 1), distanciadas una de la otra por $11 \mathrm{~km}$. Las mismas se encuentran en la ciudad de Recreo y en Campo San José.
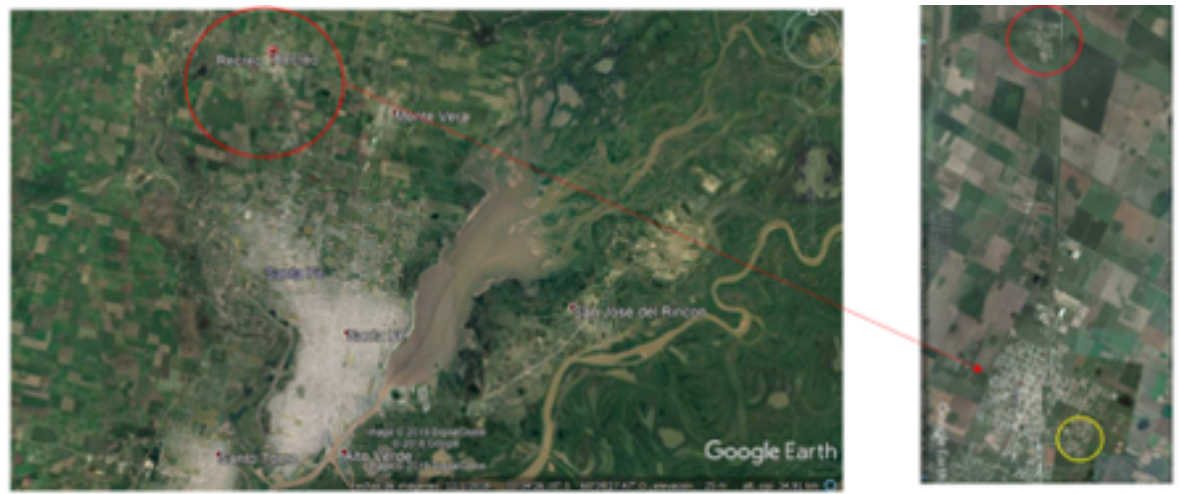

Figura 1. Ubicación de la comunidad mocoví en Recreo (en color amarillo Recreo y en rojo Campo San José). Fuente: elaboración propia.

\section{Campo San José, territorio comunitario mocoví}

A mediados de 2008, el gobierno de la provincia de Santa Fe restituyó a la comunidad mocoví 367 hectáreas ubicadas al norte de Recreo, al oeste de la Ruta $\mathrm{N}^{\circ} 11$ y en el límite con la comuna de Candioti (ver Figura 2). La adjudicación de estas tierras -conocidas como Campo San José- se hizo en el marco de la Ley provincial $\mathrm{N}^{\circ} 12.086$, con la actuación conjunta del IPAS.
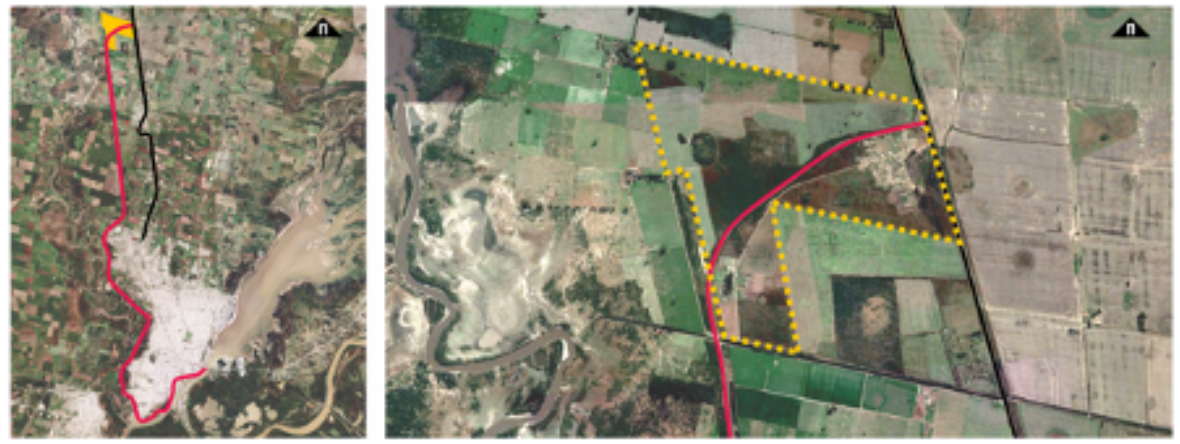

Figura 2. Campo San José. Fuente: elaboración propia.

El proceso de devolución y escrituración de tierras no escapó a un conjunto de conflictos debido a diferencias en los intereses y visiones respecto al uso de las mismas. Podemos distinguir dos partes en conflicto: por un lado, algunas familias mocovíes, acompañadas por organizaciones sociales, con el interés de ocupar las tierras restituidas para construir sus viviendas y huertas. Por otro lado, el gobierno provincial y una parte de la comunidad -encabezada por el cacique de ese momento- que intentaron evitar este asentamiento, argumentando que las tierras no debían ser utilizadas para residencias porque habían sido otorgadas únicamente con fines productivos (según la planificación de usos de suelo que había estipulado previamente el gobierno provincial) (Benzi, 2017). 
Mientras el cacique se oponía a la ocupación residencial de las tierras, se fue gestando la organización de las familias ocupantes. De esta organización, emerge como referente un joven de la comunidad ${ }^{13}$ que, para los años 2012-2016, fue elegido como nuevo cacique. Durante el proceso de ocupación de las tierras, estas figuras también se vieron afectadas por el conflicto de intereses: el nuevo cacique no fue reconocido por parte de la comunidad que residía en la ciudad de Recreo, por lo que coexistieron dos caciques con sus respectivos concejos. Así, durante esos cuatro años, la organización y la puesta en práctica de determinados proyectos, obras o actividades se vieron perjudicadas por la presencia de dos autoridades diferentes (Cardozo, Brasca y Cabré, 2018).

En la actualidad, en Campo San José habitan más de 80 familias, en su mayoría provenientes del barrio de la ciudad de Recreo, y otros nuevos habitantes migrantes del norte de Santa Fe y con presencia del área bonaerense. En cuanto a su organización sociopolítica, la máxima autoridad de la comunidad es la asamblea comunitaria, constituida por el concejo comunitario, los líderes de las familias y el cacique.

Campo San José se constituye como el nuevo territorio mocoví alejado de la ciudad, ${ }^{14}$ sin embargo, los movimientos entre los integrantes de la comunidad de Recreo son constantes. "El Campo" -como lo denominan- se presenta de forma idílica para los que aún viven en Recreo: espacio sin problemas de inseguridad, lejos de las disputas barriales con los criollos y lugar de contacto con la naturaleza. Por otro lado, los propios residentes, que tienen otra visión, se encuentran llevando constantes reclamos ante el Estado municipal y provincial para que se mejoren las condiciones de servicios públicos (electricidad, agua potable y aperturas de caminos). ${ }^{15}$

La comunidad en Campo San José se encuentra acompañada de una cooperativa de trabajo llamada TEKO. ${ }^{16}$ Una cooperativa de la ciudad de Santa Fe conformada por jóvenes profesionales, principalmente arquitectos y arquitectas, con un gran compromiso social, político y ambiental. A partir de una entrevista realizada al presidente de TEKO, conocimos que el contacto con la comunidad comenzó cuando las primeras familias decidieron vivir en el campo y, a lo largo del tiempo, fueron consolidando lazos con el consejo comunitario y llevando a cabo proyectos en conjunto vinculados a la construcción de viviendas, relevamientos territoriales (mensuras y cartografías) y trabajos de saneamiento ambiental. Destacamos la presencia de dicha organización porque es una de las motorizadoras del desarrollo de las políticas públicas en la comunidad.

13 Los nombres de las personas se resguardan de acuerdo lo establecido con la comunidad.

14 De acuerdo con estudios del INTA, la zona presenta suelos imperfectamente drenados, desarrollados en paisajes muy planos y extendidos sobre un relieve subnormal con pendientes de escaso gradiente. Con un horizonte superior muy lixiviado por la amplia infiltración derivada de su proporción de arena, estos suelos son agroecológicamente suficientes para la producción de verduras y hortalizas.

15 Estas posiciones fueron expresadas en la asamblea de comunitaria, en el mes de agosto de 2017 durante el trabajo de campo, en la cual participaron miembros de la comunidad de la ciudad de Recreo en Campo San José.

16 Para más información visitar: https://www.cooperativateko.com/ 


\section{Implementación de las políticas de promoción de ESS en la comunidad mocoví Com-Caia}

Una vez resuelto el conflicto de ocupación territorial, y a partir de la organización espacial de la comunidad con viviendas y huertas para la producción, comenzó la implementación de las políticas de promoción a la ESS. Cabe aclarar que los programas que se gestionaron tuvieron diversos momentos que logramos reconstruir a partir de entrevistas realizadas en el trabajo de campo a distintos representantes de organismos estatales (municipio, provincia y nación) y a los integrantes de la comunidad. La intervención estatal o el territorio normado a partir de las acciones concretas permitió dar continuidad al trabajo hortícola en la comunidad, por esta razón vamos a señalar dos momentos.

En el primer momento presentamos aquellas políticas específicas de la ESS del Gobierno de la Provincia de Santa Fe. En cambio, en el segundo identificamos programas de ministerios nacionales que no eran exclusivos de la ESS, pero que acompañaban a las iniciativas vinculadas a las prácticas asociativas. Particularmente, las políticas de Agricultura Familiar que giraron hacia la ESS (Caballero et al., 2011) y, por lo tanto, su reconocimiento y apoyo para la consolidación de procesos comunitarios como se menciona en el libro Economía Social y Agricultura Familiar del INTA:

(...) múltiples iniciativas que vienen ensayando diversos modos de organización socioeconómica, buscando construir alternativas incluyentes para el desarrollo de capacidades de trabajo y satisfacción de necesidades. Emergen formas alternativas de organizar la producción, la distribución, el intercambio y el consumo, ámbitos donde también asume la reivindicación de los derechos humanos, el cuidado del medioambiente y la construcción de ciudadanía. (Cittadini et al., 2010:16).

1. Políticas de la Subsecretaria de Economía Social del Ministerio de Desarrollo Social de la Provincia de Santa Fe (2011-2014).

Como indicamos con anterioridad, desde la institucionalización de la ESS en el Estado provincial, el gobierno comienza a desarrollar los programas socioproductivos. A partir del trabajo de técnicos territoriales y reuniones con parte de la comunidad, especialmente el cacique y familias de horticultores, se planificaron líneas de acciones concretas para fortalecer la actividad productiva vinculada a la producción de hortalizas y verduras durante los años 2011-2014. El proyecto COM-CAIA, como se lo denominó en la carátula de presentación ante el Ministerio, fue aprobado y ejecutado. Se financiaron programas correspondientes al Formulario $B$ para la compra de herramientas para labrar la tierra: azadas, rastrillos, horquillas, arados e insumos como semillas para la siembra.

Los técnicos territoriales, tanto del IPAS como de la subsecretaría, trabajaron en conjunto con la comunidad en una serie de capacitaciones propias de los requerimientos de la política y también ampliaron la participación a técnicos del Ministerio de Producción. Esta vinculación era necesaria porque se necesitaban de ciertos saberes específicos vinculados a la extracción de agua para el riego de las huertas. De esta manera, la intersectorialidad al interior del Estado provincial actúo de manera coordinada. 
Políticas de promoción de la Economía Social...

Acompañando a este proceso, se encontraba la cooperativa de trabajo TEKO. A nivel estatal, sus integrantes eran reconocidos como los aliados de la comunidad y eran quienes canalizaban ciertas demandas y acompañaban los reclamos ante las autoridades provinciales (MB, coordinadora del Ministerio provincial, 29 de noviembre de 2018).

No obstante, a fines del año 2014, la Subsecretaría de Economía Social tuvo un cambio de gestión, eleva su rango y se convierte en Secretaría, trasladándose al Ministerio de Producción (Cardozo y Massera, 2019). Esta situación suscitó una fuerte discusión al interior del Estado provincial y conllevó al abandono de las experiencias que se venían acompañando, como fue en el caso de la comunidad.

2. Instituto Nacional de Tecnología Agropecuaria y Subsecretaria de Agricultura Familiar del Ministerio de Agricultura, Ganadería y Pesca de la Nación (2014-2017).

A partir del año 2014 confluyen en la comunidad los técnicos del Instituto Nacional de Tecnología Agropecuaria (INTA), de la Agencia de Experimentación Rural (AER) Monte Vera y del Registro Nacional de la Agricultura Familiar (RENAF) perteneciente a la Subsecretaría de Agricultura Familiar (SAF) del Ministerio del Ministerio de Agricultura, Ganadería y Pesca de la Nación. De esta manera, se proyectaron acciones en conjunto para el fortalecimiento de la trama productiva.

Como primera medida, desde el INTA se trabajó con el Programa PROHUERTA, abasteciendo de semillas a las familias que trabajan las quintas, acompañando la actividad de cursos de formación en agroecología y manejo del suelo. Los productores destacaban la idea de una producción sin agroquímicos y reconocían el trabajo de los técnicos y técnicas que los acompañaron durante los tres años de asistencia a la comunidad. Este reconocimiento de los huerteros al acompañamiento del INTA se debe a que algunos de ellos, al trabajar bajo la agricultura convencional, acarreaban problemas de salud vinculados al manejo de agroquímicos por no contar con los recaudos necesarios en su utilización en las anteriores experiencias laborales (LP, integrante de la comunidad, octubre 2018).

Otra instancia de trabajo del INTA fue con el equipo de salud de la posta sanitaria del Ministerio de Salud Provincial que se encuentra en Campo San José. Allí se abordó la problemática de la desnutrición y acercándose a aquellas familias que se encontraban con deficiencias en la alimentación, con el objetivo de promover la soberanía alimentaria a partir de la incorporación de alimentación saludable y nutritiva a la dieta diaria. Para ello, promovieron el trabajo en la huerta y también la autoproducción en sus viviendas.

Desde el RENAF y en conjunto con la cooperativa de trabajo, se promovieron actividades de capacitación en el marco del Programa Entrenamiento para el Trabajo dependiente del Ministerio de Trabajo, Empleo y Seguridad Social de la Nación. El desarrollo del programa estaba a cargo de las técnicas de la SAF, para lo cual se planificó el dictado de cursos a un grupo de mujeres de la comunidad bajo dos actividades productivas: panificación y producción de dulces y conservas. Estas últimas se preparaban con las verduras de las quintas, siguiendo las pautas de manipulación de alimentos propuestas en la capacitación; una vez culminada la fase de elaboración, los productos se etiquetan debidamente con los datos indicativos de elaboración y vencimiento y con el sello de la SAF. 
Estos técnicos intervinieron hasta finales del año 2018, cuando fueron despedidos por decisión de reducción del personal del Ministerio de Agroindustria de la Nación del gobierno de la Alianza Cambiemos. Más allá de las ausencias, en la comunidad reconocen y valoran el trabajo desempeñado por la antropóloga y la trabajadora social integrantes del equipo interinstitucional. ${ }^{17}$

\section{Los circuitos cortos de comercialización}

Retomando la pregunta que nos hicimos en páginas anteriores: ¿se pueden llevar a cabo nuevas estrategias de organización socioespacial vinculadas a la ESS a partir de la implementación de políticas de promoción de las mismas? Estaríamos en condiciones de afirmar que los circuitos cortos de comercialización se erigen como una forma alternativa de entramados institucionales que organizan y posibilitan nuevas formas de comercialización de producción, en nuestro caso, agroecológica.

La creación de canales cortos de comercialización o circuitos de proximidad (Azevedo Da Silva, 2009 y Craviotti y Soleno Wilches, 2015) buscan acercar la producción a la ciudad a través de la organización de nodos de ventas y a partir de una estructura organizativa encadenada por una serie de acuerdos entre distintos actores ubicados entre el campo y la ciudad.

Los circuitos cortos de comercialización no sólo producen el acortamiento del canal de comercialización tradicional agroalimentario, sino que también reducen la distancia física en lo social y cultural, entre el productor y el consumidor, a través de la creación de confianza y de valores compartidos asignándociertos atributos a los productos (sanos, ecológicos, naturales, etc.) que se comercializan (Craviotti y Soleno Wilches, 2015 y Azevedo Díaz, 2009). Como indica García Guerreiro se establecen "redes o articulaciones populares [que] habilitan el (re)surgimiento de territorialidades donde la densidad de relaciones cara a cara y las experiencias compartidas son posibles" (2011:78).

Las experiencias de ESS en territorios rurales, más allá de su potencial emancipador y, en este caso, promovidas por las políticas públicas de producción de alimentos, tienden a conectarse con otras organizaciones sociales o instituciones del espacio urbano para comercializar su producción. Estas conexiones permiten distribuir verduras y hortalizas de estación a un conjunto de consumidores de la ciudad, poniendo en práctica la "deconstrucción del vínculo productor-consumidor y de relación campo-ciudad" constituyendo "ejemplos de un modo de concebir la economía que colisiona fuertemente con las tendencias del pensamiento moderno y el capitalismo globalizado" (Wharren y García Guerreiro, 2014:320).

En la comunidad mocoví Com-Caia comenzaron, a partir del año 2012, con algunas interrupciones por fenómenos meteorológicos y, desde los últimos tres años del período de estudio (2015- 2017), se reanudaron con cierta regularidad semanal, quincenal o mensual. En esta instancia de comercialización, la cooperativa de trabajo ofrece su sede como el lugar para la venta y también actúa de mediadora entre la comunidad y los compradores a través de las redes sociales, aunque en las últimas ventas el contacto con los consumidores se fue trasladando a los miembros de la comunidad porque tuvieron acceso a la tecnología y comenzaron a manejar las redes sociales.

17 Durante el trabajo de campo en el año 2018, los miembros de la comunidad preguntaban por las dos técnicas, evidenciando la creación de un vínculo que excedía la gestión de la política. 
Además, comenzaron a comercializar parte de la producción en las diferentes ferias organizadas por el Gobierno Provincial, tanto en Recreo como en Santa Fe, bajo la línea de Apoyo a la producción y circulación de productos y servicios de la ESS, y en las Ferias de Emprendedores Justo lo que Necesito, dónde la comunidad toma relevancia y visibilización a partir de la producción agroecológica como característica distintiva de otras producciones artesanales regionales.

Paralelamente, al interior de la comunidad se organizan para establecer vinculaciones con otras organizaciones, por ejemplo, con la Unión de Trabajadores de la Tierra (UTT) perteneciente a la Confederación de Trabajadores de la Economía Popular (CETEP) que a, su vez, se vinculan con la Asociación de Docentes de la Universidad Nacional del Litoral (ADUL) ofreciendo a los agremiados los bolsones de hortalizas y verduras.

$\mathrm{Al}$ conocerse y expandirse la experiencia en Santa Fe, la Organización no gubernamental Trama Tierra (http://www.tramatierra.org.ar/index.php) junto a una organización de base llamada Barrio 88 ofrecen la producción mensualmente a partir de una plataforma de comercialización virtual Chango88 (https://chango88.com.ar/) de productos regionales. Estas últimas organizaciones ofrecen las verduras, hortalizas y conservas junto a otras mercaderías de la ESS local, con un claro mensaje de consumo colaborativo y responsable.

En la figura 3 se visualiza el conjunto de instituciones y organizaciones estales y no estatales que trabajan en conjunto con la comunidad, desde la implementación de políticas de promoción de la ESS, elaborando estrategias de comercialización y distribución de la producción como hemos mencionados en párrafos anteriores.

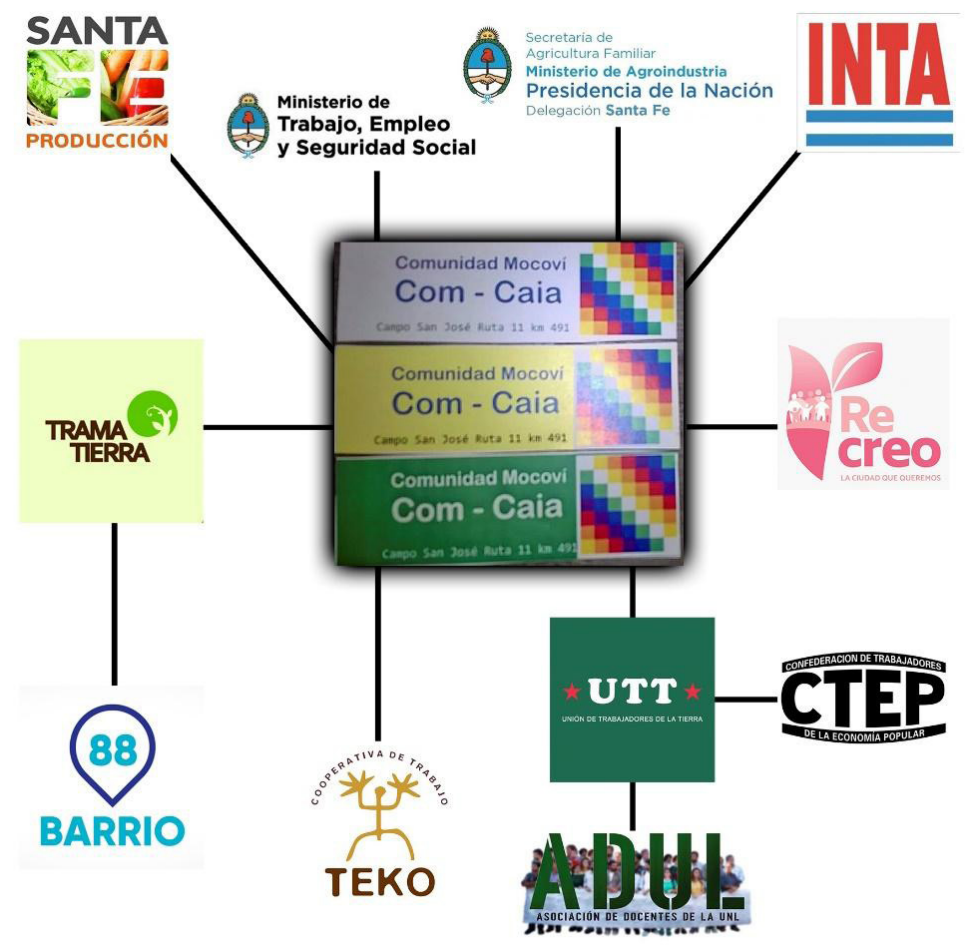

Figura 3. Instituciones estatales y no estales relacionadas con la comunidad mocoví para la producción y comercialización hortícola. Fuente: elaboración propia sobre la base de las entrevistas. 
Políticas de promoción de la Economía Social... LUCAS GABRIEL CARDOZO

En el marco de las estrategias de la comunidad mocoví, los canales cortos de comercialización contienen:

I. Fuerte contenido político: transformación del sistema agroalimentario como primera motivación, creando nuevas formas de mercados alternativos bajo una lógica contrapuesta a la hegemónica.

II. Generación de sinergias para la acción colectiva, articulación de redes para la comercialización de la producción.

III. Entramados con las políticas públicas a diferentes escalas.

IV. Valorización la producción sin agroquímicos en grupos de consumidores de la ciudad y también en los propios productores.

Para culminar, podemos encontrar diferentes puntos de ventas de la comunidad en la ciudad de Santa Fe impulsados y sostenidos conjuntamente por organizaciones sociales, donde se ofrece a un precio justo un bolsón de hortalizas y verduras. También como práctica de ESS, se determinan los eslabonamientos solidarios y se eliminan los intermediarios, estableciendo relaciones cara a cara entre los productores y consumidores. Estas socializaciones favorecen a entablar un diálogo entre productores y consumidores; conversaciones sobre la forma de producir sin agroquímicos e, incluso, se intercambian algunos consejos de cocción de los productos del contenido del bolsón. De esta forma, la comunidad acompañada de las organizaciones sociales y los agentes estatales ha logrado constituirse como un referente en la producción agroecológica.

\section{Consideraciones finales}

A través de la enunciación de lo acontecido en la comunidad Com-Caia de Campo San José en Recreo y la implementación de políticas públicas de promoción de la ESS hemos dado cuenta de cómo se elaboran nuevas estrategias de organización socioespacial para el financiamiento, la producción, comercialización y el consumo de los productos hortícolas en la puesta en funcionamiento de circuitos cortos de comercialización campo-ciudad.

De esta manera, la territorialización de las políticas públicas (des)encadenan procesos y dinámicas a lo largo del tiempo, donde el territorio normado también es el territorio como categoría de la práctica, a partir de las relaciones singulares que se negocian constantemente entre los miembros de la comunidad, técnicos y técnicas de las dependencias del Estado a diversas escalas y las organizaciones de la sociedad civil para la implementación de las políticas públicas de promoción de la ESS.

Como expusimos en la provincia de Santa Fe, la institucionalización de la política de ESS es reciente y su gestión con comunidades indígenas se realizó en un período especifico en los inicios de la creación de la Subsecretaría, en relación con el Instituto Provincial Aborigen Santafesino. Sin embargo, el proceso de territorialización de la política fue inicial para la organización de otros aspectos socioespaciales de la comunidad que estaban haciendo efectiva su territorialización en Campo San José. Seguidamente, y 
con la cuestión de las políticas de agricultura familiar en boga, se continuó trabajando la temática de la producción hortícola, sumando nuevos desafíos y cubriendo nuevas demandas.

Para finalizar, consideramos importante destacar que los sujetos promueven lazos de colaboración y solidaridad en el período de estudio que hemos analizado. El territorio, más allá de lo normando, produce un entramado con otros tipos de prácticas y de lazos sociales y espaciales. Esta producción socioespacial permite, tanto materialmente como simbólicamente, construir geografías emergentes donde la centralidad está puesta en el sujeto y no en el capital, disputando y construyendo espacios otros, creando eslabones que conectan campo-ciudad y donde se visibiliza a la población subalterna. 


\section{Q Bibliografía}

» Abramovich, A. y Vázquez, G. (2007). Experiencias de Economía Social y Solidaria en la Argentina. Estudios Fronterizos, 8(15), 121-145.

》Altschuler, B. (2013). Territorio y desarrollo: aportes de la geografía y otras disciplinas para repensarlos. Theomai, 27-28, 64-79.

»Arzeno, M. y Álvarez, G. (2017). Redes de políticas y mediación territorial en el ámbito de intervención para la agricultura familiar en Argentina. Casos en la provincia de Misiones. Documentos y Aportes en Administración Pública y Gestión Estatal, 17(29), 69-100.

» Azevedo da Silva, C. (2009). La configuración de circuitos de proximidad en el sistema alimentario: tendencias evolutivas. Documents d'Anàlisi Geogràfica, 54, 11-32.

》Beckmann E. (2018). La promoción de la Economía Social y Solidaria como estrategia de política pública. Propuestas, actores y modos de relacionamiento en la provincia de Santa Fe (2011-2015). Tesis de Maestría en Economía Social, Universidad General Sarmiento, inédita.

" Benzi, M. (2017). Territorialidades mocovíes en Santa Fe. Il Encuentro de investigadores sobre políticas sociales, urbanas y ambientales en ciudades intermedias. La política social en la ciudad de Santa Fe, presente y pasado, Santa $\mathrm{Fe}$, Facultad de Ciencias Jurídicas y Sociales, Universidad Nacional del Litoral.

» Blasco, L. y García, A. (2017). Economía social y solidaria y agenda pública: alcances, actores y objetivos en experiencias provinciales de argentina a principios de siglo XXI. SaberEs, 9(2), 177-195

" Caballero, L. (2014). No habrá otra economía... sin soberanía alimentaria. Revista Voces en el Fénix, 37, 54-71.

» Caballero, L., Dumrauf, S., González, E., Mainella, F. y Moricz, M. (2011). Los procesos organizativos de la agricultura familiar y la creación de ferias y mercados de economía social. Otra Economía, 4(7), 26-41.

» Cabré, P. (2018). Comunidades originarias en ciudades latinoamericanas: Jerarquía y diversidad de marcos legales vigentes. El caso de las comunidades tobas del Municipio de Santa Fe (Argentina). RELEG, 6(1), 21-29.

»Cardoso, M. (2018). Desequilibrios territoriales en el área de expansión urbana. Vulnerabilidad y configuración morfológica en el sector norte de Santa Fe. Geograficando, 14(2), e041. Recuperado de: https://doi. org/10.24215/2346898Xe041

" Cardozo, L. (2015). Políticas socio-productivas en la Argentina post-crisis: ¿Las políticas de Economía Social como articuladoras a escala regional? Revista Cardinalis, 4(1), 14-39.

»Cardozo, L. y Beckmann E. (2018). Las políticas de promoción de la Economía Social y Solidaria en la Provincia de Santa Fe (noviembre 2018). Documento OPPEPS $\mathrm{N}^{\circ} 3$, elaborado en el marco del Proyecto "Observatorio de las Políticas Públicas de la Economía Popular y Solidaria en la Argentina (2017/2018)", 
Secretaria de Políticas Universitarias, Ministerio de Educación, Cultura, Ciencia y Tecnología de la Nación.

» Cardozo, L. y Benzi, M. (2019). Conflictos en el rururbano norte santafesino: territorializaciones de los Com-Cai. Primer Encuentro Latinoamericano de Estudios del Rururbano. Organizado por la Facultad de Humanidades y Ciencias de la UNL (Argentina) y el Instituto de Investigaciones en Ciencias Sociales y Humanas de la Universidad de Caldas (Colombia). Santa Fe.

》 Cardozo, L., Brasca, M. y Cabré, P. (2018). Geografías indígenas: la territorialización de las comunidades Qom y Mocoví en el área metropolitana de Santa Fe (Argentina). IX Reunión Anual Comité Académico de Historia, Regiones y Fronteras Asociación De Universidades Grupo Montevideo (AUGM). Facultad de Humanidades y Ciencias de la Universidad Nacional del Litoral. 25, 26 y 27 de abril.

" Carricart, P. (2012). Cooperativas rurales y territorios en la región pampeana argentina: transformaciones sociales, económicas y organizacionales. Buenos Aires: Editorial La Colmena.

"Casaccia, R. (2016). Los alcances de la Economía Social y Solidaria en el Norte y en el Sur. +E: Revista De Extensión Universitaria, 5(5), 32-41. Recuperado de: https://doi.org/10.14409/extension.v5i5.5140

》Casella, M. (2015). El desafío de construcción de una política de promoción de la Economía Social y Solidaria. El caso del Gobierno de la Provincia de Santa Fe. Revista $+E$, 5, 142-149.

»Castelao Caruana, M. (2016). Las políticas públicas y su visión de la economía social y solidaria en Argentina. Revista Mexicana de Ciencias Políticas y Sociales, Nueva Época, 61(227), 349-378.

"Citro, S. (2006). La fiesta del 30 de agosto entre los mocovíes de Santa Fe. Buenos Aires: Universidad de Buenos Aires.

》 Cittadini, R., Caballero, L., Moricz, M. y Mainella, M. (2010). Agricultura Familiar y Economía Social. Buenos Aires: Ed. INTA.

» Cittadini R., Caballero, L., Moricz, M. y Mainella, M. (2010). Economía Social y agricultura familiar. Miradas y experiencias sobre un mismo camino. En R. Cittadini, L. Caballero, M. Moricz y M. Mainella, Agricultura Familiar y Economía Social (pp. 13-26). Buenos Aires: Ed. INTA.

》 Coraggio, J. L. (2007). Economía Social, acción pública y política (Hay vida después del neoliberalismo). Buenos Aires: CICCUS.

» Coraggio, J. L. (2012). La construcción de Otra Economía como acción política. Material del Curso Virtual "Hacía Otra Economía”. Instituto del Conurbano de la Universidad Nacional General Sarmiento.

" Coraggio, J. L. (2014). La presencia de la Economía Social y Solidaria y su institucionalización en América Latina. Documento Ocasional 7, Potencialidades y Límites de la Economía Social y Solidaria, UNRISD. Recuperado de: http://www. unrisd.org/80256B3C005BCCF9/search/7A2E9D246F8B55B2C1257CF900428C9 0?OpenDocument

»Craviotti, C. y Soleno Wilches, R. (2016). Circuitos cortos de comercialización agroalimentaria: un acercamiento desde la agricultura familiar diversificada en Argentina. Mundo Agrario, 16(33). Recuperado de: https://www.mundoagrario. unlp.edu.ar/article/vi 
» Cuatrín, E., Cardozo, L., y Alfaro, E. (2016). El Comercio Justo como alternativa para la redefinición de los vínculos mercantiles a escala local. $+E$ : Revista de Extensión Universitaria, 5(5), 104-112. Recuperado de: https://doi.org/10.14409/ extension.v5i5.5149

» Del Compare, T. (2014). La agricultura familiar campesina e indígena y la economía popular. Voces en el Fenix, 37, 62-69.

» Engelman, J., Weiss, M. L. y Valverde, S. (2017). El territorio en la ciudad; Trayectorias, nuevas configuraciones, y políticas públicas en relación a los pueblos indígenas en Argentina. RURIS - Revista Do Centro De Estudos Rurais UNICAMP, 10(2). Recuperado de: https://www.ifch.unicamp.br/ojs/index.php/ ruris/article/view/2745

»Farias, M. (2018). Contesting exclusion: Solidarity spaces and changing political subjectivities in Buenos Aires. Geo Forum. Recuperado de: https://www. sciencedirect.com/science/article/pii/S0016718518301404

»Federico-Sabeté, A. (2014). El caso de las asambleas vecinales y la recuperación de empresas en la Argentina reciente. En J. L. Coraggio (Org), La economía Social desde la periferia. Contribuciones latinoamericanas (pp. 271-316). Los Polvorines: Editorial UNGS.

» Fernández, V. R. (2001). Estrategias de desarrollo y transformación estatal. Buscando al Estado bajo el capitalismo global. Santa Fe: UNL Ediciones.

» Forni, F. y Dzembrowski, N. (2010). La economía social en Europa y en América Latina. En C. Cross y M. Berger (Comp.), La producción del trabajo asociativo. Condiciones, experiencias y prácticas en la economía social (pp. 339-355). Buenos Aires: CICCUS -Centro de Estudios e Investigaciones Laborales (CEIL-CONICET).

"Fritschy, B. y Cardoso, M. (2014). Cambios en las especializaciones productivas del rururbano norte de la ciudad de Santa Fe, Argentina. Contribuciones Científicas de GAEA, 26, 93-104.

»Gago, V. (2014). La razón neoliberal. Economías barrocas y pragmática popular. Buenos Aires: Tinta Limón Ediciones

》García Guerreiro, L. (2011). Espacios de articulación, redes autogestivas e intercambios alternativos en la ciudad de Buenos Aires. Otra Economía, 4(6), 68-82.

» Gualdieri, B. y Citro. B. (2006). Lengua, cultura e historia Mocoví en Santa Fe. Programa de Documentación de Lenguas en Peligro. Facultad de Filosofía y Letras. Buenos Aires: UBA.

» Haesbaert, R. (2018). De categoria de análise a categoria da prática: A multiplicidade do território numa perspectiva latino-americana En F. Fridman, L. Alem Gennari y S. Lencioni (Coord.), Políticas públicas e territórios: onze estudos latino-americanos (pp. 267-288). Ciudad Autónoma de Buenos Aires: CLACSO.

» Hintze, S. (2003). Trueque y Economía Social. Los Polvorines, Buenos Aires: Universidad Nacional General Sarmiento: Prometeo Libros.

»Hintze, S. (2007). Políticas sociales argentinas 1990-2006. En M. Vuotto (Coord.), La co-construcción de políticas públicas en el campo de la Economía Social (pp. 111-135). Buenos Aires: Prometeo Libros.

» Hintze, S. (2010). La política es un arma cargada de futuro. Buenos Aires: CLACSO. 
»Hintze, S. (2013). Políticas públicas para Otra Economía. En R. Maidana, y V. Constanzo (Eds.), Hacia otra economía (pp. 31-39). Los Polvorines: Ediciones UNGS.

»Hintze, S. (2014). Las políticas públicas para la economía social y solidaria: cuestiones en debate. Voces en el Fenix, 37, 20-27.

» Hintze, S., Deux Marzi, M. V. y Costa, M. (2011). Los organismos públicos de promoción del trabajo asociativo autogestionado en la Argentina. En S. Hintze y C. Danani (Comp.), Protecciones y desprotecciones. La seguridad social en la Argentina 1990-2010 (pp. 233-281). Buenos Aires: Ediciones UNGS.

» Hopp, M. (2012). Políticas sociales de empleo en la Argentina postconvertibilidad. Un análisis comparativo de planes de desarrollo socio-productivo. En M. Di Virgilio, P. Boniolo y M. Otero (Comp.), Viejos Problemas, nuevas alternativas. Estrategias de lucha contra la pobreza: Alternativas desde el Sur (pp. 135-168). CLACSO: Buenos Aires.

» Hopp, M. (2017). Transformaciones en las políticas sociales de promoción de la economía social y del trabajo en la economía popular en la Argentina actual. Cartografías Del Sur. Revista De Ciencias, Artes y Tecnología, 6, 19-40.

》 INTA. (2012). Censo Hortícola 2012 del cinturón verde de Santa Fe. Recuperado de: https://inta.gob.ar/documentos/censo-horticola-2012-del-cinturon-verde-desanta-fe

» Jurado, E. y Cardozo, L. (2016). La cuestión espacial en la economía social y solidaria: una lectura de procesos cooperativos a partir de estudios geográficos. SaberEs, 8(1), 23-42.

" Laville, J.L. y Eme, B. (2004). Renovación y diversidad de prácticas. En J.L Laville (Dir.), Economía social y solidaria: una visión europea (pp. 1-25). Buenos Aires: OSDE-UNGS-Editorial Altamira.

» López Sandoval, M., Robertsdotter, A. y Paredes, M. (2017). Space, Power and Locality: the Contemporary Use of Territorio in Latin American Geography. Journal of Latin American Geography, 16(1), 43-67.

» Mantovani, G. y Peralta Flores, M. (2015). Bordes e Interfases. Miradas sobre el paisaje del periurbano norte del Gran Santa Fe, Argentina. VII Seminario Internacional de Investigación en Urbanismo, Barcelona-Montevideo.

» Massera, M. y Cardozo, L. (2019). Producción de políticas a escala subnacional: institucionalización de la Economía Social y Solidaria en la provincia de Santa Fe (Argentina). Revista Temas y Debates, 37, 119-134.

» Muñoz, R. (2017a). De la perplejidad a una acción monetario-financiera contrahegemónica. Contexto y desafíos ante la especulación financiera global. Ciencias Económicas, 1, 123-139. Recuperado de: https://doi.org/10.14409/rce. v1i0.6900

" Muñoz, R. (2017b). Políticas de Economía Social y Solidaria en Municipios del Conurbano Bonaerense. Avances de su institucionalización. Documento de Trabajo del Observatorio del Conurbano. Instituto del Conurbano, Universidad Nacional General Sarmiento. Recuperado de: http://observatorioconurbano.ungs. edu.ar/wp-content/uploads/nota-central-R-Mu\%C3B1oz.pdf

» Mutuberría Lazarini, V. (2010). El campo de la Economía Social en debate. En A. García (Coord.), Repensando la economía social (pp. 11-28). Cuaderno de trabajo 
NNo 86. Buenos Aires: Ediciones del Centro Cultural de la Cooperación Floreal Gorini.

» North, P. y Huber, U. (2004). Alternative Spaces of the Argentinazo. Antipode, 36, 963-984.

"Orzi, R. (2012). Moneda Social y mercados solidarios II. La moneda como lazo social. Lujan: Universidad Nacional de Lujan-Ediciones CICCUS.

» Orzuza, S., Rocío Moltoni, R., García, T. y Ochoteco, L. (2015). Red de Comercio Justo del Litoral (Argentina). Un ejemplo de la construcción de mercados alternativos al hegemónico. Revista del OSERA, 12, 27-45.

》 Oxoby, P. (2010). Una aproximación a las divergencias e implicaciones de los distintos abordajes a la Economía Social: países centrales europeos y América Latina. Otra Economía, 4(6), 153-166.

»Paula, C. Q. de (2019). Geografias das ausências e geografias das emergências. GEOUSP Espaço E Tempo (Online), 23(1), 095-111.

»Quiroga Díaz, N. (2009). Economías feminista, social y solidaria. Respuestas heterodoxas a la crisis de reproducción en América Latina. Revista Iconos, 33, 77-89.

»Rebón, M. y Roffler, E. (2008) Balances y Perspectivas de las Políticas Socioproductivas: El Caso del Plan Nacional Manos a la Obra. Revista Medio Ambiente y Urbanización, 68(1), 75-94.

»Rebón, M. y Roffler, E. (2006) Políticas socioproductivas e inclusión social: ¿Hacia un nuevo modelo de políticas sociales? La experiencia del Plan Nacional "Manos a la Obra". Documento presentado para Concurso RIDELC, Ciudad de Buenos Aires, Argentina.

»Rebón, M. y Salse, G. (2003) Plan Manos a la obra: dificultades y desafíos de su gestión. Foro Federal de Investigadores y docentes, Ministerio de Desarrollo Social, Buenos Aires, Argentina.

»Rebón, M., Salse, G. y Roffler, E. (2004) Nueva gestión para una nueva política social. Il Congreso Nacional de Políticas Sociales, Mendoza, Argentina.

» Robledo, L. (2014). Ferias y mercados vuelven al barrio. Revista Armar la ciudad. Licenciatura en Urbanismo, Universidad General Sarmiento, 26-29.

》Sánchez, J. (2017) Institucionalidad y políticas para la economía popular y solidaria: balance de la experiencia ecuatoriana. En J.L. Coraggio, Miradas sobre la economía Social y solidaria en América Latina (pp. 85-101). Los Polvorines: Ediciones UNGS.

»Santarcángelo, J., Wydler, A. y Padín, J. M. (2019) Política económica y desempeño industrial en la Argentina durante el gobierno de la Alianza Cambiemos. Balance y perspectivas. Revista de Ciencias Sociales, segunda época, 10(35), 171-188.

»Svampa, M. (2000) Desde abajo: la transformación de las identidades sociales. Buenos Aires: Editorial Biblos.

»Tobío, O. (2010). Entre el Estado y los movimientos sociales: sobre la recreación de lo público en función de la planificación territorial. Scripta Nova, 14(331).

»Vuotto, M. (2009). Algunas referencias sobre la noción de trabajo asociado en el siglo XIX. Revista Economía, 28, 103-127. 
»Vuotto, M. (2011). El cooperativismo de Trabajo en la Argentina: Contribuciones para el diálogo social. OIT, Programa Regional para la Promoción al Diálogo y la cohesión social en América Latina, serie Documento de Trabajo № 217.

»Vuotto, M. (2014). Economía Social: precisiones conceptuales y algunas experiencias históricas. Los Polvorines: Ediciones UNGS.

»Wanderley, F. (2016). La Economía Solidaria y Comunitaria en Bolivia. Revista de la Academia, 21, 57-75.

»Wharren, J. y García Guerreiro, L. (2014). Campesinado, territorios en disputas y nuevas estrategias de comercialización de la producción campesina en Argentina. Revista Veredas, 28, 297-342.

"Wyczykier, G. (2009). De la dependencia a la autogestión laboral. Sobre la reconstrucción de experiencias colectivas de trabajo en Argentina contemporánea. Buenos Aires: UNGS-Prometeo.

»Zibechi, R. (2011). Políticas sociales, gobiernos progresistas y movimientos antisistémicos. Otra Economía, 4(6), 32-42.

\section{Hemerografía}

»Gandulfo, A. (Mayo 30, 2017). La Economía Social y Solidaria crece con la resistencia popular (Especial para sitio IADE-RE). Recuperado de: http://www.iade. org.ar/noticias/la-economia-social-y-solidaria-crece-con-la-resistencia-popular

" Lutzky, L. (Mayo 22, 2019). Como en el 2001: vuelve el trueque a Argentina. Recuperado de: https://www.24con.com/nota/194168-como-en-el-2001-vuelve-eltrueque-a-argentina/

» Notiamérica (2018). El trueque regresa a Argentina como método de supervivencia. Recuperado de: https://www.notimerica.com/sociedad/noticiatrueque-regresa-argentina-metodo-supervivencia-20181010150025.html

Lucas Gabriel Cardozo / cardozo.lucas@gmail.com

Licenciado en Geografía (UNL). Maestrando en Economía Social (UNGS) y doctorando en Humanidades con mención en Geografía (UNL). Actualmente becario del Instituto de Humanidades y Ciencias Sociales del Litoral (IHuCSo) de doble dependencia CONICET - UNL. Docente de la carrera de Trabajo Social de la FCJS, UNL. Ha publicado artículos en revistas nacionales: Cardinales (UNC), Revista del Centro de Estudios de Sociología del Trabajo (UBA), FAVE, Sección Ciencias Agrarias (UNL), SaberES (UNR), Temas y Debates (UNR), Geograficando (UNLP), +E: Revista de Extensión Universitaria (UNL) e internacionales: REDES (UNISC, Brasil), RBEUR (ANPUR, Brasil) y Cooperativismo y Desarrollo (Colombia) y Revista Estudios del Desarrollo Social: Cuba y América Latina (FLACSO, Cuba). 